\title{
Impact of Entrepreneurial Self-Construction on Entrepreneurial Intention: Moderating Role of Institutions
}

\author{
Qiong Gui*, Wenqing Chen, Xuming Zhang \\ School of Public Affair, University of Science and Technology of China, Hefei, China \\ Email: *guiqiong@mail.ustc.edu.cn, chenwenqingchn@163.com,17862886619@163.com
}

How to cite this paper: Gui, Q., Chen, W. Q., \& Zhang, X. M. (2021). Impact of Entrepreneurial Self-Construction on Entrepreneurial Intention: Moderating Role of Institutions. Journal of Human Resource and Sustainability Studies, 9, 212-230. https://doi.org/10.4236/jhrss.2021.92014

Received: March 30, 2021

Accepted: April 25, 2021

Published: April 28, 2021

Copyright (c) 2021 by author(s) and Scientific Research Publishing Inc. This work is licensed under the Creative Commons Attribution International License (CC BY 4.0).

http://creativecommons.org/licenses/by/4.0/

\begin{abstract}
The paper discusses the influence of individual self-construction on entrepreneurial intention from the perspective of self-cognition while considering the institutional context at the national level. The research contends that individual entrepreneurial self-construction has a positive impact on entrepreneurial intentions and the institutional context moderates the relationship between individual entrepreneurial self-construal and entrepreneurial intention. These relationships are stronger in countries with regulation, cognition, and normative which favour the creation, growth, and management of new businesses. Analysis of Global Entrepreneurship Monitoring (GEM) survey data from 60 countries and regions supports the hypotheses. The conclusions provide important implications for research of entrepreneurial intentions and the soundness of the entrepreneurial system.
\end{abstract}

\section{Keywords}

Entrepreneurial Self-Construction, Entrepreneurial Intention, Institutional Context

\section{Introduction}

Entrepreneurial activities are critical to economic and social development (Cornwall, 1998). Whereas entrepreneurial intentions are the first step in a typical long-term entrepreneurial process (Krueger, 1993), which profoundly affects entrepreneurs behaviour (Fishbein \& Ajzen, 1980). While entrepreneurial intention as a cognitive structure widely used in entrepreneurial literature (Thompson, 2009) has long been a subject of academic attention.

What are the influencing factors of entrepreneurial intention? This paper at- 
tempts to study entrepreneurial intentions from the perspective of self-construction. Existing research ideas on the influencing factors of entrepreneurial intention are mainly divided into individual perspective and organisational perspective. From the perspective of individuals, such as individual characteristics (active personality (Crant, 1996), uncertainty tolerance for risk-taking tendency ((Koh, 1995), etc.), individual background (family background, educational background, work experience (Crant, 1996), entrepreneurial experience (Singer, 1995), Individual perceived characteristics (e.g. self-efficacy (Bandura \& Walters, 1977)) and perceived risk resilience (Bullough, Renko, \& Myatt, 2014) have essential effects on individual entrepreneurial intentions. Organisational perspectives such as social culture (Malhotra \& McCort, 2001), entrepreneurship education (Noel, 2001) and so on also affect the individual entrepreneurial intentions to varying degrees.

On the whole, we found that previous research only discussed one or a few specific individual factors or social factors that affect entrepreneurial intention. It did not analyse the dynamic formation process of entrepreneurial intentions and rarely integrated the organisation. The interaction with individual elements, the cognitive performance and preference propensity of individuals in the process of entrepreneurial role construction are still unknown in this field. In this study, we try to develop the concept of self-construction into the subjective cognitive level of the individual and the construction of self-character and explore the dynamic formation of entrepreneurial intention from the perspective of self-cognition.

We believe that self-construction is likely to have a positive impact on entrepreneurial intentions. The concept of self-construction is based on the study of the formation and development of self-concepts by psychology and anthropology. It was proposed by Markus and Kitayama. It was initially used to describe the individual's understanding of the relationship between self and others (Markus \& Kitayama, 1991). It is divided into independent self-construction and Interdependent self-construction, although individuals have two types of self-construction, a specific cultural environment encourages the development of one of these constructs (Cross, Hardin, \& Swing, 2009). As the concept develops, scholars have different understandings of self-construal. Lam (Lam, 2006) believes that self-construction refers to the extent to which an individual considers himself to be in a social relationship. This paper defines the individual's self-construction as the construction of self-concept, which is the psychological selfperception of the self (Hardin, Leong, \& Bhagwat, 2004), individual's cognising and understanding during the process of growing up. In the context of entrepreneurship, self-construction can be understood as the individual's understanding of the entrepreneurial role model or the individual's own knowledge, skills, experience and other aspects of entrepreneurial knowledge. Reviewing research on self-construction mainly exists in the field of psychology, such as the study of gender differences in self-construal (Cross \& Madson, 1997), the relationship between self-construction and social cognition (Cross, Gore, \& Morris, 2003). Self-construction studies on the impact of self-esteem (Hannover, Birk- 
ner, \& Pöhlmann, 2006). Studies have shown that self-construction has an important effect on cognitive, motivational, emotional and other psychological characteristics (Markus, Kitayama, \& Heiman, 1996). The entrepreneurial intention reflects a subjective attitude of potential entrepreneurs in their future entrepreneurial activities (Bird, 1988; Carr \& Sequeira, 2007; Krueger, Reilly, \& Carsrud, 2000; Wilson, Kickul, \& Marlino, 2007). It is the intrinsic cognition, preference and behavioural tendency of entrepreneurs for entrepreneurship (De Noble, Jung, \& Ehrlich, 1999). Therefore, self-construction is likely to have an impact on individual entrepreneurial intentions, and it is necessary to further study the relationship between self-construction and entrepreneurial intentions.

The present paper also addresses the contingent role of the institution on the main effect. We use the three-dimensional concept of the institution (Busenitz, Gomez, \& Spencer, 2000; Scott, 2008). The formation of individual entrepreneurial intentions is the result of constant communication and interaction between individual factors and institutional environment. The institution is likely to have an impact on the relationship between individual entrepreneurial self-construction and entrepreneurial intention. The institutional context can help individuals to better act by complying with the rules and norms of the system and analyse and judge the legitimacy, appropriateness and value orientation of their own cognition and behaviour in a complex market environment. Therefore, it is necessary to consider the institutional background at the national level and analyse how the institutional context regulates the relationship between individual entrepreneurial self-construction and the formation of entrepreneurial intentions.

The contributions of this research are mainly reflected in the following aspects. First, our study attempts to provide a new way of thinking about the influencing factors of entrepreneurial intentions. Self-construction promotes entrepreneurial intentions. Individuals continuously learn and accumulate entrepreneurial knowledge, skills and experience in the dynamic process of building entrepreneurial roles, and expand entrepreneurial cognition to strengthen entrepreneurial intentions. Second, our research focuses on the interactivity at the individual and macro levels and shifts the research perspective from individual to macro cross-layer. We develop a multi-level framework that contributes to the intersection of entrepreneurial theory, social cognitive theory, and institutional theory. We use 181,281 large representative samples from 60 countries to test our model hypothesis in the context of a widely developed system. It may be institutionalised for entrepreneurial self-construction of entrepreneurial intentions. The resulting role provides a new interpretation of the optimal institutional context in which entrepreneurial self-construction may promote entrepreneurial intentions.

\section{Theoretical Background and Hypothesis Development}

\subsection{Entrepreneurial Self-Construct and Entrepreneurial Intention}

In general, the intent to explore purposeful behaviour is critical to our under- 
standing of the behaviour (Fishbein \& Ajzen, 1980). Intention has long been considered a reliable predictor of behaviour, and entrepreneurial intent is the beginning of the entrepreneurial process (Thompson, 2009). Entrepreneurship intention is the best predictor of entrepreneurial behaviour, reflecting a subjective attitude of potential entrepreneurs in their future entrepreneurial activities (Krueger et al., 2000; Wilson et al., 2007), is the intrinsic cognition, preference, and behavioural tendency of entrepreneurs for entrepreneurship (De Noble et al., 1999). We describe entrepreneurial intentions as a state of perception: an individual-recognised idea or decision that targets entrepreneurship.

First of all, entrepreneurial self-construction is the construction of the concept of self-playing entrepreneurs, repeated re-organisation and re-engineering in the process, so the cultivation of ability, the acquisition of knowledge and the accumulation of experience play an essential role in entrepreneurial intention. Based on the planned behaviour theory (Krueger Jr., Reilly, \& Carsrud, 2000), entrepreneurial intentions are considered to be developed by the perception of the desirability and feasibility of entrepreneurial behaviour (Fishbein \& Ajzen, 1980). Individuals with high entrepreneurial self-construction often have more knowledge reserves, stronger business capabilities, more relevant experience and experience have laid a cognitive foundation for entrepreneurial behaviour, raising their expectations of entrepreneurial viability and entrepreneurial success. It is anti-strike, anti-risk ability and courage to overcome difficulties, rapid adjustment of the determination and continuous learning and accumulation continue to carry out the entrepreneurial role of the construction process. Therefore, individuals with high entrepreneurial self-construction are more likely to generate entrepreneurial intentions.

Thus, we offer the following hypothesis:

H1: Individual entrepreneurial self-construction has a positive impact on entrepreneurial intentions.

\subsection{Moderating Effect of the Institution}

Social cognition theory suggests that interactions between environmental factors, personal factors, and individual behaviours influence an individual's ultimate behaviour (Bullough et al., 2014; Wood \& Bandura, 1989). The institutional theory provides an ideal basis for the study of individual arguments in context. The system defines what is legal, appropriate, and subconsciously oriented in an objective sense (Bruton, Ahlstrom, \& Li, 2010). Previous studies have shown that institutions influence entrepreneurial behaviour. The institutional context directly shapes the individual's social-cognitive characteristics or mitigates the relationship between individual cognitive characteristics and near-end selection behaviour. Generally speaking, we believe that individuals are more likely to generate entrepreneurial intentions when they are in a favourable entrepreneurial system and have a higher entrepreneurial self-construction. Regarding the discussion of the system, we adopt the three-dimensional concept of 
institutional background (Busenitz et al., 2000; Scott, 2008), which divides the system into three dimensions: regulation, cognition and normativeness, and studies the institutional background for entrepreneurial self-construction and individual entrepreneurial intention. The regulatory aspect reflects policies and regulations related to entrepreneurship (Bowen \& De Clercq, 2008). While the cognitive aspect indicates the extent to which knowledge related to entrepreneurship is domestically available (Busenitz \& Lau, 1996). Such as the national education system attaches importance to the development and growth of new businesses (Levie \& Autio, 2008). The normative dimension reflects the extent to which the people of the country consider entrepreneurship to be an ideal career choice, that is, the degree to which society recognises entrepreneurship (De Clercq, Danis, \& Dakhli, 2010).

\subsubsection{Regulatory Dimension of the Institution}

The regulatory dimension of the system restricts, regulates, and regulates behaviour, and has the function of both restricting and enabling social behaviour. The regulatory dimension represents a model of rational actors based on sanctions and hermeneutics that guides behaviour through rules, oversight, and enforcement (Bruton et al., 2010). In the context of entrepreneurship, the regulatory dimension reflects policies and regulations related to entrepreneurship (Bowen \& De Clercq, 2008). This dimension influences the entrepreneurial process through various policy measures (Lim, Morse, Mitchell, \& Seawright, 2010). The regulatory dimension of the system determines the degree to which people are willing and willing to allocate available social cognitive resources to entrepreneurial activities (Baumol, 1996). Such activities provide permission and convenience for the entrepreneurial process.

For countries where laws, support programs, and legislation lead to new business development, growth and management, their regulations and opportunities effectively reduce the obstacles and risks to entrepreneurship (Baumol \& Strom, 2007). It also increases the productivity of the entrepreneurial system, decreases person perceptions on entrepreneurship challenges and requirements of the expertise, skills and even encouraged the people to participate in entrepreneurial activities. Individual efforts may be used more smoothly and more centrally for entrepreneurship, enhancing the motivation for individuals to continue to accumulate entrepreneurial learning, enabling individuals to gain a stronger belief in entrepreneurial success, and then inspiring individuals with higher self-construction to generate stronger entrepreneurship. The intention, more energy is invested in entrepreneurial behaviour.

Thus, we provide the following hypothesis:

H2: The regulatory dimension of the institutional context moderates the relationships between individuals entrepreneurial self-construal and their entrepreneurial intention, such that these relationships are stronger in countries with policies, support programs, and regulations that favour the creation, growth, and management of new businesses. 


\subsubsection{Cognitive Dimension of the Institution}

The cognitive dimension of the institutional context refers to the knowledge and cognitive categories shared by individuals within a country (Kostova \& Roth, 2002). In the context of entrepreneurship, the cognitive dimension reflects the extent to which knowledge about entrepreneurship is widely disseminated (Busenitz et al., 2000), such as the importance of national education systems for entrepreneurial development and growth (Levie \& Autio, 2008). This dimension is increasingly essential for entrepreneurial research in how society creates a cultural environment that embraces and encourages entrepreneurship (Bosma \& Levie, 2010; Harrison, 2008; Li, 2011), which deals with Does a country's education system specifically address entrepreneurial relevance (such as the creation and growth of new businesses) (Bowen \& De Clercq, 2008; Reynolds et al., 2005).

The focus on entrepreneurship in the education system not only prepares individuals for the specific skills needed to develop their entrepreneurship but also promotes universal awareness of entrepreneurship as a possible career choice (Souitaris, Zerbinati, \& Al-Laham, 2007). On the one hand, the education system that emphasises entrepreneurial development and growth helps individuals to develop and accumulate the knowledge, skills and experience needed for individual entrepreneurship in the process of self-construction through objective teaching and practice and promotes the individual's concept of playing the role of entrepreneur. The construction process has increased the possibility of the formation of its entrepreneurial intentions. On the other hand, the degree to which the national education system attaches importance to entrepreneurial development and growth also reflects the social orientation of entrepreneurship.

High social entrepreneurship cognition and the role model of successful entrepreneurs can motivate individuals to continuously learn and imitate the motivations of successful entrepreneurs' entrepreneurial paths and entrepreneurial experiences, making them firmer in entrepreneurship and more determined to start a business.

Thus, we offer the following hypothesis:

H3: The cognitive dimension of the institutional context moderates the relationships between individuals entrepreneurial self-construal and their entrepreneurial intention, such that these relationships are stronger in countries where the education system pays more considerable attention to the creation, growth, and management of new businesses.

\subsubsection{Normative Dimension of the Institution}

In general, the normative dimension of a country's institutional environment encompasses behavioural models accepted through various social interactions (Bruton et al., 2010). The normative dimension usually consists of values (what are preferred or considered correct) and norms (how to do things that are consistent with these values) that further consciously establish the basic rules that people follow (Scott, 2008). In the context of entrepreneurship, the normative dimension reflects the extent to which the people of the country consider entre- 
preneurship to be an ideal career choice, that is, the degree to which society recognises entrepreneurship (De Clercq et al., 2010). This choice may depend on whether the culture of the country emphasises the value of individual initiative and self-fulfilment (Baughn, Chua, \& Neupert, 2006), such as how social media views entrepreneurship (Reynolds et al., 2005).

The normative dimension influences the relationship between self-construction and individual entrepreneurial intention by subtly revealing the social value of entrepreneurship and social needs. When society's recognition of entrepreneurship is low, entrepreneurs often cannot be positively praised and encouraged, or even regarded as negative individuals, and their entrepreneurial careers are often disadvantaged (Bruton, Ahlstrom, \& Obloj, 2008). Therefore, even if the individual has a high entrepreneurial self-construction, there will be no risk of public opinion to carry out entrepreneurial activities. When society recognises entrepreneurship to a higher degree, society emphasises the value of self-creation and self-realisation. Entrepreneurship becomes an ideal career choice. Individuals with high self-construction will be more likely to form entrepreneurial preferences consistent with social entrepreneurship orientation.

Thus, we offer the following hypothesis in Figure 1:

H4: The normative dimension of the institutional context moderates the relationships between individuals entrepreneurial self-construal and their entrepreneurial intention, such that these relationships are stronger in countries where entrepreneurial careers are considered desirable.

\section{Method}

\subsection{Sample}

We selected the data from 60 countries and regions in the Global Entrepreneurship

Institutional context

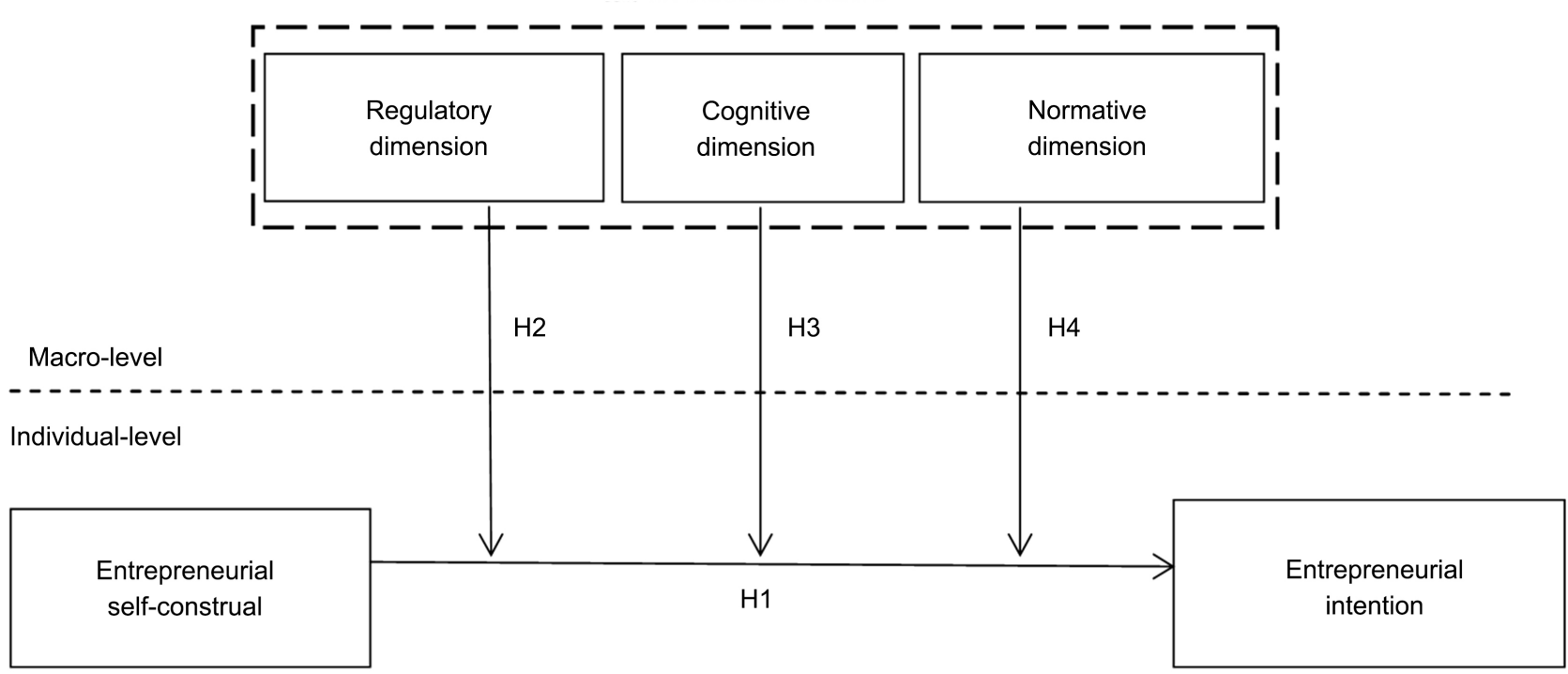

Figure 1. Theoretical model. 
Monitoring (GEM) survey to test the above assumptions. The GEM project began in the late 1990s and is dedicated to the collection of entrepreneurial data surveys and entrepreneurial behaviours around the world. The GEM survey data covers a wide range of sources, reliable sources, and collects program standards to ensure the validity of data structures and measurements (Reynolds et al., 2005).

The individual-level variable data in this study was derived from the GEM Adult Sex Survey (APS), and the national-level institutional background data was obtained from the GEM National Expert Survey (NES). In all personal-level data reports, $49.7 \%$ of individuals believe that they have the knowledge, skills or experience required for entrepreneurship, with an average of about $0.5 .21 .7 \%$ of individuals have an intention to start a business in the next three years, with an average of 0.22 . At the national level, the average level of regulation of the institutional context is 0.046 , ranging from -0.76 to 0.96 ; the average level of cognitive dimensions is 0.048 , the range is -0.8 to 1.02 ; the average of the normative dimension is 0.069 , the range is -0.71 to 1.42 .

\subsection{Measures}

In general, individual-level variables in GEM survey data have been used in previous entrepreneurial literature (Autio, Pathak, \& Wennberg, 2013; Boudreaux, Nikolaev, \& Klein, 2019); the institutional dimension at the national level as a moderator has also been tried in previous literature (De Clercq et al., 2010; Lim, Oh, \& De Clercq, 2016). The specific questions used in the GEM survey ${ }^{1}$ provide definitions of all variables used in the study.

\subsubsection{Dependent Variable}

We follow the usual practice of defining entrepreneurship as an attempt to create a new business or new risks, such as self-employment, new business organisations, or expansion of existing businesses. Specifically, the entrepreneurial intention is extracted from the GEM variable "dustup". If the individual wants to launch or try a new business or new risk within the next three years, he or she is considered to have the intention to start a business in the next three years, then the selection value is 1 , otherwise the value is 0 .

\subsubsection{Independent Variable}

We used the measurement of entrepreneurial self-construction in the GEM Adults Survey (APS). Specifically, the entrepreneurial self-construction is extracted from the GEM variable "subskill". If the individual knows that he has the knowledge, skills, or experience required for entrepreneurship, the value is chosen to be 1 , otherwise the value is 0 .

\subsubsection{Moderator Variable}

The institutional background is the adjustment variable of this study. In the di-

${ }^{1}$ https://www.gemconsortium.org/about/gem. 
vision of the system, the three-dimensional concept of institutional background is adopted, and the system is divided into three dimensions: regulation, cognition and normative. To measure these three dimensions, we used the GEM National Expert Survey (NES) to verify the scale, which was evaluated using the Likert five-point score.

The regulatory dimension of the institutional context reflects policies and regulations related to entrepreneurship. We use the average score of experts in the survey to evaluate government entrepreneurship-related support policies, programs, and entrepreneurial-related laws and regulations.

The cognitive dimension of the institutional background reflects the extent to which knowledge related to entrepreneurship is popularised in China, such as the importance the national education system attaches to entrepreneurial development and growth. We use the average score of the survey's experts' assessment of the state's education system in entrepreneurship, including higher education and vocational education.

The normative dimension of the institutional background reflects the extent to which the people of the country consider entrepreneurship to be an ideal career choice, that is, the degree to which society recognises entrepreneurship. We use the average score of the survey's assessment of the desirability of national entrepreneurship careers.

\subsubsection{Control Variable}

A lot of research on entrepreneurial intentions shows that some other characteristics of individuals have different degrees of influence on the formation of individual entrepreneurial intentions. To ensure the reliability of the empirical research results, according to previous research, the individual's gender, age, education level, working status and income will affect the entrepreneurial will to some extent, and choose the individual's gender, age and education level. As a control variable can significantly reduce the potential risk of the research model. In the GEM survey, gender is divided into two categories: "male" and "female". The age of the entrepreneur is counted according to the age group. The education level is based on the five standards from specialist to postdoctoral. The work status is based on full-time or part-time work. Income, unemployment, retired or three categories of students, income is divided into three levels of low, medium and high. In addition, since this paper explores the institutional role of the national level as an environmental factor, it is necessary to control some national-level characteristic variables.

This study selects the nature of the economy that reflects the stage of national economic development as the control variable and divides it into three stages: factor-driven, efficiency-driven, and innovation-driven to further ensure the validity of the research results.

\section{Analysis and Results}

Table 1 provides the mean, standard deviation, and correlation matrix for each 
variable in the study. The correlation of most of the variables in this study is relatively small, below 0.3 , and the correlation between the cognitive dimension and the normative dimension of the institutional background is 0.630 , but this value is still within a moderate range, below 0.7 . Therefore, the impact on our analysis is relatively small.

In addition, in the process of data analysis, this study examined that the Cronbach's a coefficient of each variable was higher than 0.9 , indicating that the measurement scales of each variable in this study have good internal consistency and meet the requirements of further processing. As shown in Table 2. At the same time, the Kaiser-Meyer-Olkin metric is greater than 0.8, Bartlett's sphericity test corresponds to a probability $P$-value of 0.00 , less than 0.01 , EFA test results show that the scale has high validity. In addition, to test the multicollinearity, we calculated the VIF value of each regression equation. The highest VIF value is 1.950 , which is much lower than the upper limit of $10 \mathrm{VIF}$, indicating that there is no problem with multicollinearity.

Table 3 shows the results of the logistic regression model. Model 1 analyses all control variables, including individual gender, age, education, work status, and income. The regression results show that the formation ratio of individual entrepreneurial intentions under the factor-driven economy and the efficiency-driven

Table 1. Summary statistics and correlation matrix.

\begin{tabular}{|c|c|c|c|c|c|c|c|c|c|c|c|c|c|}
\hline Variables & Mean & SD & 1 & 2 & 3 & 4 & 5 & 6 & 7 & 8 & 9 & 10 & 11 \\
\hline 1) Economy 3 & 2.35 & 0.688 & & & & & & & & & & & \\
\hline 2) Workstatus 3 & 1.48 & 0.737 & $0.030^{\star *}$ & & & & & & & & & & \\
\hline 3) Income 3 & 1.95 & 0.821 & $0.025^{\star *}$ & $-0.190^{\star *}$ & & & & & & & & & \\
\hline 4) Education 5 & 3.00 & 1.060 & $0.209^{* *}$ & $-0.109^{\star *}$ & $0.277^{\star *}$ & & & & & & & & \\
\hline 5) Gender & 0.51 & 0.500 & $-0.009^{\star *}$ & $0.117^{\star *}$ & $-0.090^{* *}$ & $-0.026^{\star *}$ & & & & & & & \\
\hline 6) Age & 4.12 & 1.441 & $0.175^{\star *}$ & $0.133^{\star *}$ & $-0.026^{* *}$ & $-0.080^{\star *}$ & $0.015^{\star *}$ & & & & & & \\
\hline $\begin{array}{l}\text { 7) Regulatory } \\
\text { dimension }\end{array}$ & 0.0455 & 0.38014 & $0.197^{\star *}$ & $-0.030^{\star *}$ & $0.088^{\star *}$ & $0.011^{\star *}$ & $-0.007^{\star \star}$ & $0.085^{\star *}$ & & & & & \\
\hline $\begin{array}{l}\text { 8) Cognitive } \\
\text { dimension }\end{array}$ & 0.0479 & 0.36764 & $0.178^{\star *}$ & -0.003 & $0.076^{\star *}$ & $0.059^{\star *}$ & $0.010^{* *}$ & $0.078^{\star *}$ & $0.506^{\star *}$ & & & & \\
\hline $\begin{array}{l}\text { 9) Normative } \\
\text { dimension }\end{array}$ & 0.0690 & 0.43304 & $0.092^{* *}$ & $-0.049^{\star \star}$ & $0.077^{\star *}$ & $0.110^{* *}$ & $0.009^{* *}$ & $0.053^{\star *}$ & $0.505^{* *}$ & $0.630^{* *}$ & & & \\
\hline $\begin{array}{l}\text { 10) Entrepreneurial } \\
\text { self-construal }\end{array}$ & 0.50 & 0.500 & $-0.157^{\star \star}$ & $-0.168^{\star \star}$ & $0.113^{\star *}$ & $0.056^{* *}$ & $-0.123^{\star \star}$ & $-0.019^{\star *}$ & $-0.039^{\star \star}$ & $-0.024^{\star \star}$ & 0.005 & & \\
\hline $\begin{array}{l}\text { 11) Entrepreneurial } \\
\text { intention }\end{array}$ & 0.22 & 0.412 & $-0.276^{\star *}$ & $-0.098^{\star *}$ & $0.027^{\star \star}$ & $-0.022^{\star *}$ & $-0.052^{\star *}$ & $-0.175^{\star *}$ & $-0.056^{\star *}$ & $-0.093^{\star \star}$ & 0.004 & $0.267^{* *}$ & \\
\hline
\end{tabular}

${ }^{\star *} p<0.01$. 
Table 2. Results of validity and reliability assessment.

\begin{tabular}{ccc}
\hline Variables & Cronbach's $\alpha$ & Kaiser-Meyer-Olkin \\
\hline Regulatory dimension & 0.936 & 0.845 \\
Cognitive dimension & 0.920 & 0.832 \\
Normative dimension & 0.959 & 0.870 \\
\hline
\end{tabular}

Table 3. Results of logistic regression analyses.

\begin{tabular}{|c|c|c|c|c|c|c|c|c|}
\hline Variables & Model 1 & Mode 2 & Mode 3-1 & Mode 4-1 & Mode 3-2 & Mode 4-2 & Mode 3-3 & Modl 4-3 \\
\hline \multicolumn{9}{|l|}{ Economy 3} \\
\hline Economy 3(1) & $-0.402^{* * *}$ & $-0.283^{* * *}$ & $-0.217^{\star * *}$ & $-0.222^{* * *}$ & $-0.2143^{* * *}$ & $-0.227^{* * *}$ & $-0.211^{* * *}$ & $-0.220^{\star * *}$ \\
\hline Economy 3(2) & $-1.561^{* * *}$ & $-1.364^{* * *}$ & $-1.558^{* * *}$ & $-1.566^{* * *}$ & $-1.518^{* * *}$ & $-1.527^{* * *}$ & $-1.553^{* * *}$ & $-1.563^{\star * *}$ \\
\hline \multicolumn{9}{|l|}{ Workstatus 3} \\
\hline Workstatus 3(1) & $-0.095^{* * *}$ & $0.032 \dagger$ & $-0.039 \dagger$ & $-0.039 \dagger$ & $-0.053^{*}$ & $-0.056^{*}$ & -0.030 & -0.031 \\
\hline Workstatus 3(2) & $-0.716^{* * *}$ & $-0.506^{* * *}$ & $-0.607^{\star * *}$ & $-0.606^{* * *}$ & $-0.619^{* * *}$ & $-0.619^{* * *}$ & $-0.601^{* * *}$ & $-0.602^{\star * *}$ \\
\hline \multicolumn{9}{|l|}{ Income } \\
\hline Income (1) & $-0.058^{\star *}$ & $-0.109^{* * *}$ & $-0.156^{* * *}$ & $-0.154^{* * *}$ & $-0.143^{* * *}$ & $-0.142^{* * *}$ & $-0.167^{* * *}$ & $-0.167^{\star * *}$ \\
\hline Income (2) & $0.082^{* * *}$ & $-0.020^{* * *}$ & -0.029 & -0.031 & -0.007 & -0.004 & -0.024 & -0.024 \\
\hline \multicolumn{9}{|l|}{ Education 5} \\
\hline Edu 5(1) & $-0.455^{\star * *}$ & $-0.407^{* * *}$ & $-0.452^{\star * *}$ & $-0.447^{* * *}$ & $-0.428^{* * *}$ & $-0.431^{* * *}$ & $-0.457^{* * *}$ & $-0.460^{\star * *}$ \\
\hline Edu 5(2) & $-0.338^{\star * *}$ & $-0.323^{* * *}$ & $-0.280^{* * *}$ & $-0.273^{* * *}$ & $-0.251^{* * *}$ & $-0.256^{* * *}$ & $-0.300^{* * *}$ & $-0.302^{\star * *}$ \\
\hline Edu 5(3) & $-0.163^{* * *}$ & $-0.182^{\star * *}$ & $-0.154^{* * *}$ & $-0.146^{* * *}$ & $-0.148^{* * *}$ & $-0.155^{\star * *}$ & $-0.177^{\star * *}$ & $-0.180^{\star * *}$ \\
\hline Edu 5(4) & $0.116^{* *}$ & 0.046 & $0.084 \dagger$ & $0.090^{*}$ & 0.068 & 0.060 & 0.061 & 0.057 \\
\hline Gender (1) & $-0.255^{\star * *}$ & $-0.165^{\star * *}$ & $-0.122^{\star * *}$ & $-0.125^{\star * *}$ & $-0.115^{\star * *}$ & $-0.119^{\star * *}$ & $-0.128^{* * *}$ & $-0.131^{\star * *}$ \\
\hline Age & $-0.027^{\star * *}$ & $-0.029^{* * *}$ & $-0.025^{* * *}$ & $-0.025^{* * *}$ & $-0.025^{\star * *}$ & $-0.025^{* * *}$ & $-0.025^{* * *}$ & $-0.025^{\star * *}$ \\
\hline $\begin{array}{l}\text { Entrepreneurial } \\
\text { self-construal }\end{array}$ & & $1.241^{\star * *}$ & $1.261^{* * *}$ & $1.251^{* * *}$ & $1.256^{* * *}$ & $1.250^{* * *}$ & $1.262^{\star * *}$ & $1.240^{* * *}$ \\
\hline Regulatory dimension & & & $0.107^{\star * *}$ & $-0.136^{* * *}$ & & & & \\
\hline $\mathrm{RD} *(\mathrm{E}$ Self-C$)$ & & & & $0.371^{* * *}$ & & & & \\
\hline Cognitive dimension & & & & & $-0.176^{* * *}$ & $-0.470^{* * *}$ & & \\
\hline$C D *(E$ Self $-C)$ & & & & & & $0.418^{* * *}$ & & \\
\hline Normative dimension & & & & & & & $0.206^{* * *}$ & 0.041 \\
\hline$N D *(E$ Self $-C)$ & & & & & & & & $0.248^{\star * *}$ \\
\hline Cox \& Snell $\mathrm{R}^{2}$ & 0.105 & 0.151 & 0.160 & 0.161 & 0.161 & 0.161 & 0.161 & 0.161 \\
\hline Nagelkerke $\mathrm{R}^{2}$ & 0.158 & 0.229 & 0.246 & 0.247 & 0.246 & 0.247 & 0.247 & 0.247 \\
\hline Hosmer-Lemeshow & $54.51^{\star * *}$ & $125.36^{* * *}$ & $88.46^{\star * *}$ & $80.94^{* * *}$ & $122.03^{* * *}$ & $88.63^{\star * *}$ & $101.68^{\star * \star}$ & $107.19^{\star * *}$ \\
\hline Wald & $36,196 \cdot 17^{\star \star *}$ & $34,782.98^{* * *}$ & $28,284.47^{\star \star *}$ & $28,284.47^{\star \star \star}$ & $28,284.47^{* * *}$ & $28,284.47^{* * *}$ & $28,284 \cdot 47^{\star * \star}$ & $28,284.48^{\star * *}$ \\
\hline
\end{tabular}

Note: Entrepreneurial self-construal; E Self-C, Regulatory dimension; RD, Cognitive dimension; $\mathrm{CD}$, Normative dimension; $\mathrm{ND},{ }^{\dagger} p<0.10,{ }^{*} p<0.05,{ }^{* *} p<$ $0.01,{ }^{* * *} p<0.00$ 
economy is 0.201 and $0.669(\beta 1=-0.402, \beta 2=-1.561, p<0.001)$. The female entrepreneurial intention ratio is $0.903(\beta=-0.027, p<0.001)$ for males; the entrepreneurial intention ratio of unemployed individuals and retired or individual students is 0.910 and 0.4899 for full-time or part-time working individuals, respectively ( $\beta 1=-0095, \beta 2=-0.716, p<0.001)$; as the individual's educational level increases, the entrepreneurial intention ratio increases (Exp (B) gradually increases, $p<0.001)$; The growth of the entrepreneurial intention ratio is rising (Exp (B) gradually increases, $p<0.001$ ); as the individual income increases, the entrepreneurial intention formation ratio shows an increasing trend (Exp (B) increase progressively, $p<0.001)$. Model 2 analyses the influence of independent self-construction on entrepreneurial intentions. The results show that individuals with entrepreneurial self-construction have a 3.405 times more entrepreneurial intention than individuals without entrepreneurial self-construction $(\beta=$ $1.241, p<0.001$ ), Hypothesis 1 is supported, indicating that individuals with entrepreneurial self-construction are more likely to form entrepreneurial intentions than individuals who recognize that they do not possess the skills, knowledge, and experience required for entrepreneurship. Model 3-1 and Model 4-1 analyse the regulatory role of the regulatory dimension of the institutional context on the relationship between individual self-construction and entrepreneurial intention. Model 3-1 is placed into the regulatory dimension of the institutional context of regulatory variables, and Model 4-1 analyses the interaction of individual self-construction and regulatory dimensions. According to Model 4-1, the regulatory dimension of the institutional context positively regulates the relationship between individual self-construction and entrepreneurial intention ( $\beta=$ $0.371, p<0.001)$. Therefore, Hypothesis 2 is validated, i.e., in policies, support programs, and regulations. For countries that are conducive to the creation, growth, and management of new businesses, individuals with entrepreneurial self-construction are more likely to generate entrepreneurial intentions than individuals without entrepreneurial self-construction. Model 3-2 and Model 4-2 analyse the regulatory role of the cognitive dimension of institutional background on the relationship between individual self-construction and entrepreneurial intention. Model 3-2 is placed into the cognitive dimension of the institutional context of regulatory variables, and Model 4-2 analyses the interaction of individual self-construction and cognitive dimensions. According to Model 4-2, the cognitive dimension of the institutional context positively regulates the relationship between individual self-construction and entrepreneurial intention ( $\beta=0.418, p<0.001)$, that is, in countries where the education system pays more attention to the creation, growth, and management of new businesses. Compared with individuals who do not have entrepreneurial self-construction, individuals with entrepreneurial self-construction are more likely to generate entrepreneurial intentions. Hypothesis 3 is supported. Model 3-3 and Model 4-3 analyse the regulatory role of the normative dimension of the institutional context on the relationship between individual self-construction and entrepreneurial in- 
tention. Model 3-3 is placed into the normative dimension of the institutional context of regulatory variables, and Model 4-3 analyses the interaction of individual self-construction and normative aspects. According to Model 4-3, the normative dimension of the institutional context positively regulates the relationship between individual self-construction and entrepreneurial intention ( $\beta=$ 0.248, $p<0.001$ ), and Hypothesis 4 is supported, indicating that in countries considered to require entrepreneurial career, compared with individuals who do not have entrepreneurial self-construction, individuals with entrepreneurial self-construction are more likely to generate entrepreneurial intentions.

\section{Discussion and Conclusion}

This study explores the relationship and mechanism between individual selfconstruction and the formation of entrepreneurial intentions in consideration of the institutional background at the national level and adopts the three-dimensional concept of institutional background. It is divided into regulatory dimension, cognitive dimension and normative dimension, and discusses the role of each dimension in regulating the relationship between individual self-construction and its entrepreneurial intention formation. We selected the Global Entrepreneurship Monitoring (GEM) survey data from 60 countries and regions from 2007 to 2016 for analysis. The empirical analysis shows that individual self-construction contributes to the formation of entrepreneurial intentions; the entrepreneurial system of the country in which the individual is located the background has a positive adjustment effect on the relationship between individual self-construction and the formation of entrepreneurial intention in the three dimensions of regulation, cognition and normative.

The existing research shows that entrepreneurial intention is the beginning of the entrepreneurial process, can reliably predict entrepreneurial behaviour, and exploring entrepreneurial intention is very important for us to understand entrepreneurial behaviour. Previous studies on the influencing factors of entrepreneurial intentions are broadly divided into individual perspectives and environmental perspectives. The research on the influencing factors at the individual level mainly includes individual characteristics, individual background, individual perception, etc. However, few studies explore the influence of self-construction on individual entrepreneurial intentions. We develop the concept of self-construction into individual subjective self-concept. The construction of cognitive level and self-character explores how self-construction affects the formation of entrepreneurial intentions. Based on the planned behaviour theory, entrepreneurial intention is considered to be derived from the perception of the desirability and feasibility of entrepreneurial behaviour. Individuals with high entrepreneurial self-construction often have more knowledge reserves, stronger business capabilities, and richer relevant experiences and experiences, which have laid a cognitive foundation for their entrepreneurial behaviour and improved their feasibility for entrepreneurship. Sexual expectations 
and the belief in entrepreneurial success have reinforced their resistance to combat, risk resistance and courage to overcome difficulties, rapid adjustment of decisiveness and continuous learning to accumulate the entrepreneurial role of the construction process. Therefore, individuals with high entrepreneurial selfconstruction are more likely to generate entrepreneurial intentions.

This study further explores the role of the institutional context of individuals in regulating the relationship between individual self-construction and the formation of entrepreneurial intentions. We have found that institutional regulation is more conducive to the development of entrepreneurial countries, which is conducive to the creation, growth and management of new enterprises in terms of policies, support projects and regulations. These can provide more adequate policy support for individual entrepreneurship and can be objectively effective. Reducing the barriers of entrepreneurial activities and restricting unfair entrepreneurial competition, the results show that the individual self-construction and institutional regulation dimensions have strong complementary effects. The more favourable entrepreneurial system regulation makes individuals have greater policy support and fairer entrepreneurial competition. Stronger beliefs in entrepreneurial success and stronger motivation to build entrepreneurial roles are more likely to generate entrepreneurial intentions under the influence of institutional regulation. Since the institutional cognition is more conducive to entrepreneurial development, the education system is more focused on the creation, growth and management of new enterprises, so the knowledge related to entrepreneurship is more prevalent in China. The education system that attaches importance to entrepreneurial development can help individuals develop the knowledge, skills and experience needed for entrepreneurship in the process of self-construction through objective teaching and practice. At the same time, the attention to entrepreneurial issues in the education system helps to form a high degree of social entrepreneurship. It is known that individuals are more willing to learn entrepreneurial knowledge under the encouragement of successful entrepreneurs, pay attention to the improvement of entrepreneurial cognition level, and strengthen their entrepreneurial intentions. The study also found that institutional norms are more conducive to entrepreneurial development, and their society recognises entrepreneurship more. Institutional norms that are conducive to entrepreneurship often show that entrepreneurship is an ideal career choice, entrepreneurship has a high social value, entrepreneurial activities are required by society to guide individuals' individual goals and social goals to converge, and encourage individuals to generate entrepreneurial intentions. The study reveals that the institutional background not only provides legal, appropriate, and subconscious channels for individuals to engage in entrepreneurial activities through regulation, cognition and norms but also affects the extent to which individual social cognitive resources are mobilised and leads to the possibility of high entrepreneurial intentions.

The contributions of this research are mainly reflected in the following aspects. 
First, this study has important theoretical significance. First, in the existing research on entrepreneurial intentions, there are few attempts to use self-construction as an antecedent variable. Studies have shown that self-construction has an essential influence on cognitive, motivation, emotion and other psychological characteristics, and entrepreneurial intention as a subjective cognition in the field of entrepreneurship, it is likely to be influenced by individual self-construction. Our research attempts to provide a new way of thinking for entrepreneurial intention research. Second, in general, the cross-level discussion of entrepreneurial intention research is not sufficient. In fact, social cognition theory advocates that environmental factors, personal factors and personal behaviours affect the individual's final behaviour. The formation process of entrepreneurial intention is determined by the interaction between human and environment. Therefore, the extensive institutional background will affect individual self-constructing a relationship with entrepreneurial intentions. Our research focuses on interpersonal and organisational interactions and shifts the research perspective from individual to organisational cross-layer. We have developed a multi-level framework to explore the optimal institutional context in which entrepreneurial self-construction may promote entrepreneurial intentions. The institutional background of the national level as an environmental factor has empirically tested the regulatory role of individual entrepreneurial self-construction and entrepreneurial intention and contributed to the intersection of entrepreneurial theory, social cognitive theory and institutional theory. Second, this study has significant application value for the establishment of entrepreneurial practice and entrepreneurship system. From the perspective of system, we provide a new explanation for the role of individual self-construction in the generation of entrepreneurial intention, and explore the multi-dimensional nature of the background of entrepreneurial system: the three dimensions of institutional background actually constitute a continuum, and one end is legal sanctions. At the other end is moral domination. The regulatory, cognitive, and normative dimensions respectively create a channel for instrumental, orthodox, and appropriateness for individuals to engage in entrepreneurial activities through compulsory, imitative, and normative diffusion mechanisms, affecting individuals. The direction of perception of the self-construction process, in turn, determines the extent to which individual social cognitive resources may be mobilised to lead to the formation of high entrepreneurial intentions.

Our study has limitations that provide several directions for future research. First, regarding the data scales of the two variables of individual self-construction and their entrepreneurial intentions, we use the variable measurement in the GEM Adult Oral Survey (APS), which has certain rationality, but it uses two-point classification. Tables are not conducive to the analysis of the extent and changes of individual cognitive characteristics. Future research can improve measurement methods and focus on the extent of continuous internal changes in individual cognitive characteristics, which will enhance the persuasiveness of re- 
search. Second, in this study, entrepreneurial intention is the entrepreneur's internal cognition, preference and behavioural tendency for entrepreneurship, and limits entrepreneurial intention to a subjective attitude that reflects whether potential entrepreneurs are engaged in entrepreneurial activities in the future. This includes both irrational cognitive entrepreneurial behaviours and rational entrepreneurial behaviours based on objective conditional analysis. Future research can generalise the scope of research objects and enhance the universality of research. Thirdly, this study draws on social cognition theory and institutional theory to explore the influence of individual self-construction on its entrepreneurial intention and the adjustment of institutional background at the national level as an environmental factor. However, we have not explicitly compared the different degrees of the various dimensions of the institutional background to regulate the relationship between individual self-construction and the formation of entrepreneurial intentions and did not discuss the specific background differentiation of each country or region. Future research can further refinement and discussion, taking into account the formation process of different dimensions of the entrepreneurial system background, will strengthen the universal applicability of research and enhance the practical significance of research.

\section{Conflicts of Interest}

The authors declare no conflicts of interest regarding the publication of this paper.

\section{References}

Autio, E., Pathak, S., \& Wennberg, K. (2013). Consequences of Cultural Practices for Entrepreneurial Behaviors. Journal of International Business Studies, 44, 334-362. https://doi.org/10.1057/jibs.2013.15

Bandura, A., \& Walters, R. H. (1977). Social Learning Theory(Vol. 1). Englewood Cliffs, NJ: Prentice-Hall.

Baughn, C. C., Chua, B. L., \& Neupert, K. E. (2006). The Normative Context for Women's Participation in Entrepreneruship: A Multicountry Study. Entrepreneurship Theory and Practice, 30, 687-708. https://doi.org/10.1111/j.1540-6520.2006.00142.x

Baumol, W. J. (1996). Entrepreneurship: Productive, Unproductive, and Destructive. Journal of Business Venturing, 11, 3-22. https://doi.org/10.1016/0883-9026(94)00014-X

Baumol, W., \& Strom, R. (2007). Entrepreneurship and Economic Growth. Strategic Entrepreneurship Journal, 1, 233-237. https://doi.org/10.1002/sej.26

Bird, B. (1988). Implementing Entrepreneurial Ideas: The Case for Intention. Academy of Management Review, 13, 442-453. https://doi.org/10.5465/amr.1988.4306970

Bosma, N. S., \& Levie, J. (2010). Global Entrepreneurship Monitor 2009 Executive Report.

Boudreaux, C. J., Nikolaev, B. N., \& Klein, P. (2019). Socio-Cognitive Traits and Entrepreneurship: The Moderating Role of Economic Institutions. Journal of Business Venturing, 34, 178-196. https://doi.org/10.1016/j.jbusvent.2018.08.003

Bowen, H. P., \& De Clercq, D. (2008). Institutional Context and the Allocation of Entrepreneurial Effort. Journal of International Business Studies, 39, 747-767. https://doi.org/10.1057/palgrave.jibs.8400343 
Bruton, G. D., Ahlstrom, D., \& Li, H. L. (2010). Institutional Theory and Entrepreneurship: Where Are We Now and Where Do We Need to Move in the Future? Entrepreneurship Theory and Practice, 34, 421-440. https://doi.org/10.1111/j.1540-6520.2010.00390.x

Bruton, G. D., Ahlstrom, D., \& Obloj, K. (2008). Entrepreneurship in Emerging Economies: Where Are We Today and Where Should the Research Go in the Future. Entrepreneurship Theory and Practice, 32, 1-14. https://doi.org/10.1111/j.1540-6520.2007.00213.x

Bullough, A., Renko, M., \& Myatt, T. (2014). Danger Zone Entrepreneurs: The Importance of Resilience and Self-Efficacy for Entrepreneurial Intentions. Entrepreneurship Theory and Practice, 38, 473-499. https://doi.org/10.1111/etap.12006

Busenitz, L. W., \& Lau, C.-M. (1996). A Cross-Cultural Cognitive Model of New Venture Creation. Entrepreneurship Theory and Practice, 20, 25-40. https://doi.org/10.1177/104225879602000403

Busenitz, L. W., Gomez, C., \& Spencer, J. W. (2000). Country Institutional Profiles: Unlocking Entrepreneurial Phenomena. Academy of Management Journal, 43, 994-1003. https://doi.org/10.2307/1556423

Carr, J. C., \& Sequeira, J. M. (2007). Prior Family Business Exposure as Intergenerational Influence and Entrepreneurial Intent: A Theory of Planned Behavior Approach. Journal of Business Research, 60, 1090-1098. https://doi.org/10.1016/j.jbusres.2006.12.016

Cornwall, J. R. (1998). The Entrepreneur as a Building Block for Community. Journal of Developmental Entrepreneurship, 3, 141-148.

Crant, J. M. (1996). The Proactive Personality Scale as a Predictor of Entrepreneurial Intentions. Journal of Small Business Management, 34, 42-49.

Cross, S. E., \& Madson, L. (1997). Models of the Self: Self-Construals and Gender. Psychological Bulletin, 122, 5-37. https://doi.org/10.1037/0033-2909.122.1.5

Cross, S. E., Gore, J. S., \& Morris, M. L. (2003). The Relational-Interdependent Self-Construal, Self-Concept Consistency, and Well-Being. Journal of Personality and Social Psychology, 85, 933-944. https://doi.org/10.1037/0022-3514.85.5.933

Cross, S. E., Hardin, E. E., \& Swing, B. G. (2009). Independent, Relational, and Collective-Interdependent Self-Construals. In M. R. Leary, \& R. H. Hoyle (Eds.), Handbook of Individual Differences in Social Behavior (pp. 512-526). New York: The Guilford Press.

De Clercq, D., Danis, W. M., \& Dakhli, M. (2010). The Moderating Effect of Institutional Context on the Relationship between Associational Activity and New Business Activity in Emerging Economies. International Business Review, 19, 85-101. https://doi.org/10.1016/j.ibusrev.2009.09.002

De Noble, A. F., Jung, D., \& Ehrlich, S. B. (1999). Entrepreneurial Self-Efficacy: The Development of a Measure and Its Relationship to Entrepreneurial Action. In Frontiers of Entrepreneurship Research (pp. 73-87). Wellesley, MA: Babson College.

Fishbein, M., \& Ajzen, I. (1980). Understanding Attitudes and Predicting Social Behavior. Hoboken, NJ: Prentice-Hall.

Hannover, B., Birkner, N., \& Pöhlmann, C. (2006). Ideal Selves and Self-Esteem in People with Independent or Interdependent Self-Construal. European Journal of Social Psychology, 36, 119-133. https://doi.org/10.1002/ejsp.289

Hardin, E. E., Leong, F. T., \& Bhagwat, A. A. (2004). Factor Structure of the Self-Construal Scale Revisited: Implications for the Multidimensionality of Self-Construal. Journal of Cross-Cultural Psychology, 35, 327-345. 
https://doi.org/10.1177/0022022104264125

Harrison, L. E. (2008). The Central Liberal Truth: How Politics Can Change a Culture and Save It from Itself. Oxford: Oxford University Press.

Koh, H. C. (1995). Factors Associated with Entrepreneurial Inclination: An Empirical Study of Business Undergraduates in Hong Kong. Journal of Small Business \& Entrepreneurship, 12, 29-41. https://doi.org/10.1080/08276331.1995.10600487

Kostova, T., \& Roth, K. (2002). Adoption of an Organizational Practice by Subsidiaries of Multinational Corporations: Institutional and Relational Effects. Academy of Management Journal, 45, 215-233. https://doi.org/10.2307/3069293

Krueger Jr., N. F., Reilly, M. D., \& Carsrud, A. L. (2000). Competing Models of Entrepreneurial Intentions. Journal of Business Venturing, 15, 411-432. https://doi.org/10.1016/S0883-9026(98)00033-0

Krueger, N. (1993). The Impact of Prior Entrepreneurial Exposure on Perceptions of New Venture Feasibility and Desirability. Entrepreneurship Theory and Practice, 18, 5-21. https://doi.org/10.1177/104225879301800101

Krueger, N., Reilly, M., \& Carsrud, A. (2000). Entrepreneurial Intentions: A Competing Models Approach. Journal of Business Venturing, 15, 411-432. https://doi.org/10.1016/S0883-9026(98)00033-0

Lam, B. T. (2006). Self-Construal and Socio-Emotional Development among Vietnamese-American Adolescents: An Examination of Different Types of Self-Construal. International Journal of Behavioral Development, 30, 67-75. https://doi.org/10.1177/0165025406062125

Levie, J., \& Autio, E. (2008). A Theoretical Grounding and Test of the GEM Model. Small Business Economics, 31, 235-263. https://doi.org/10.1007/s11187-008-9136-8

Li, Y. (2011). Emotions and New Venture Judgment in China. Asia Pacific Journal of Management, 28, 277-298. https://doi.org/10.1007/s10490-009-9145-4

Lim, D. S. K., Oh, C. H., \& De Clercq, D. (2016). Engagement in Entrepreneurship in Emerging Economies: Interactive Effects of Individual-Level Factors and Institutional Conditions. International Business Review, 25, 933-945.

https://doi.org/10.1016/j.ibusrev.2015.12.001

Lim, D. S., Morse, E. A., Mitchell, R. K., \& Seawright, K. K. (2010). Institutional Environment and Entrepreneurial Cognitions: A Comparative Business Systems Perspective. Entrepreneurship Theory and Practice, 34, 491-516. https://doi.org/10.1111/j.1540-6520.2010.00384.x

Malhotra, N. K., \& McCort, J. D. (2001). A Cross-Cultural Comparison of Behavioral Intention Models-Theoretical Consideration and an Empirical Investigation. International Marketing Review, 18, 235-269. https://doi.org/10.1108/02651330110396505

Markus, H. R., \& Kitayama, S. (1991). Culture and the Self: Implications for Cognition, Emotion, and Motivation. Psychological Review, 98, 224-253. https://doi.org/10.1037/0033-295X.98.2.224

Markus, H. R., Kitayama, S., \& Heiman, R. J. (1996). Culture and "Basic" Psychological Principles. In E. T. Higgins, \& A. W. Kruglanski (Eds.), Social Psychology: Handbook of Basic Principles (pp. 857-913). New York: The Guilford Press.

Noel, T. (2001). Effects of Entrepreneurial Education on Intent to Open a Business. Frontiers of Entrepreneurship Research, 5, 78-146.

Reynolds, P., Bosma, N., Autio, E., Hunt, S., De Bono, N., Servais, I. et al. (2005). Global Entrepreneurship Monitor: Data Collection Design and Implementation 1998-2003. Small Business Economics, 24, 205-231. https://doi.org/10.1007/s11187-005-1980-1 
Scott, W. R. (2008). Institutions and Organizations: Ideas and Interests. Thousand Oaks, CA: Sage.

Singer, B. (1995). Contours of Development. Journal of Business Venturing, 10, 303-329. https://doi.org/10.1016/0883-9026(94)00025-P

Souitaris, V., Zerbinati, S., \& Al-Laham, A. (2007). Do Entrepreneurship Programmes Raise Entrepreneurial Intention of Science and Engineering Students? The Effect of Learning, Inspiration and Resources. Journal of Business Venturing, 22, 566-591. https://doi.org/10.1016/j.jbusvent.2006.05.002

Thompson, E. R. (2009). Individual Entrepreneurial Intent: Construct Clarification and Development of an Internationally Reliable Metric. Entrepreneurship Theory and Practice, 33, 669-694. https://doi.org/10.1111/j.1540-6520.2009.00321.x

Wilson, F., Kickul, J., \& Marlino, D. (2007). Gender, Entrepreneurial Self-Efficacy, and Entrepreneurial Career Intentions: Implications for Entrepreneurship Education. Entrepreneurship Theory and Practice, 31, 387-406. https://doi.org/10.1111/j.1540-6520.2007.00179.x

Wood, R., \& Bandura, A. (1989). Social Cognitive Theory of Organizational Management. Academy of Management Review, 14, 361-384.

https://doi.org/10.5465/amr.1989.4279067 